\title{
Potential future denervation targets
}

The human sympathetic nervous system has an important regulatory role. In its dysfunctional hyperexcitatory state, it can lead to multiple pathologies. The renal sympathetic nerves play a significant role in these pathological states. Percutaneous renal sympathetic denervation (RSDN) allows for safe minimally invasive selective denervation of the renal sympathetic nerves. RSDN has been shown to be safe and efficacious in blood pressure reduction in earlier nonblinded SYMPLICITY HTN-1 and -2 trials. In Europe, it is approved for a select group of truly resistant severe essential hypertension. However, its real efficacy is now in doubt with the blinded SYMPLICITY HTN-3 trial that showed no significant difference in change in office and mean 24-h ambulatory systolic blood pressure between RSDN and sham-procedure arms. This review will look at the potential targets for percutaneous RSDN-heart failure, cardiac arrhythmias and kidney disease, sleep-disordered breathing and insulin resistance.

Keywords: cardiac arrhythmia $\bullet$ heart failure $\bullet$ insulin resistance $\bullet$ kidney disease $\bullet$ renal sympathetic denervation $\bullet$ resistant hypertension • sleep-disordered breathing $\bullet$ sympathetic nervous system

The sympathetic nervous system (SNS) has an important regulatory role in the body. In its dysfunctional hyperexcitatory state, this SNS activation can lead to multiple deleterious effects. The renal sympathetic nerves, around the renal artery adventitia, play a significant role in the pathophysiology of these pathological states. Renal sympathetic denervation (RSDN) is a novel percutaneous endovascular catheter technology that allows safe selective denervation of the renal sympathetic nerves located in the adventitia of the renal arteries. This review will look at the potential targets for percutaneous RSDN.

\section{SNS in physiology \& pathology}

The SNS has an important regulatory role in the body. However, in its dysfunctional counterproductive hyperexcited state, SNS activation can lead to many deleterious effects (Figure 1) [1,2].

The renal sympathetic nerves include a rich arborizing network of efferent and afferent nerves in the renal artery adventitia and contribute a significant role in the pathophysiology of these pathological states (Box 1) [1].

\section{Rationale for \& description of percutaneous RSDN}

The rationale for percutaneous RSDN lies in pathetic impact on the target organs. RSDN is a novel percutaneous catheter technology that allows safe selective denervation of the renal sympathetic nerves located in the adventitia of the renal arteries [3]. Briefly [2], this is a minimally invasive procedure, without the need for permanent device implantation. Femoral artery access is obtained, followed by intra-arterial heparin, aiming for a target-activated clotting time more than $250 \mathrm{~s}$. Both renal arteries are then cannulated in sequence using a guide catheter. Before treating each artery, the administration intraarterial nitroglycerine through the renal the interruption of the excitatory renal sym-

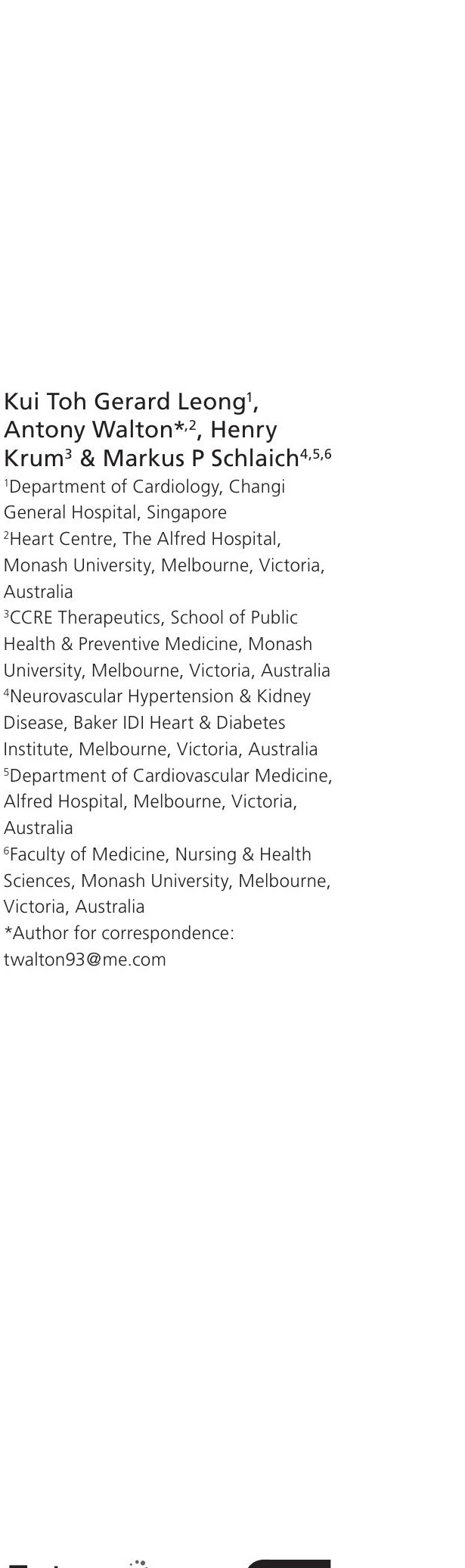

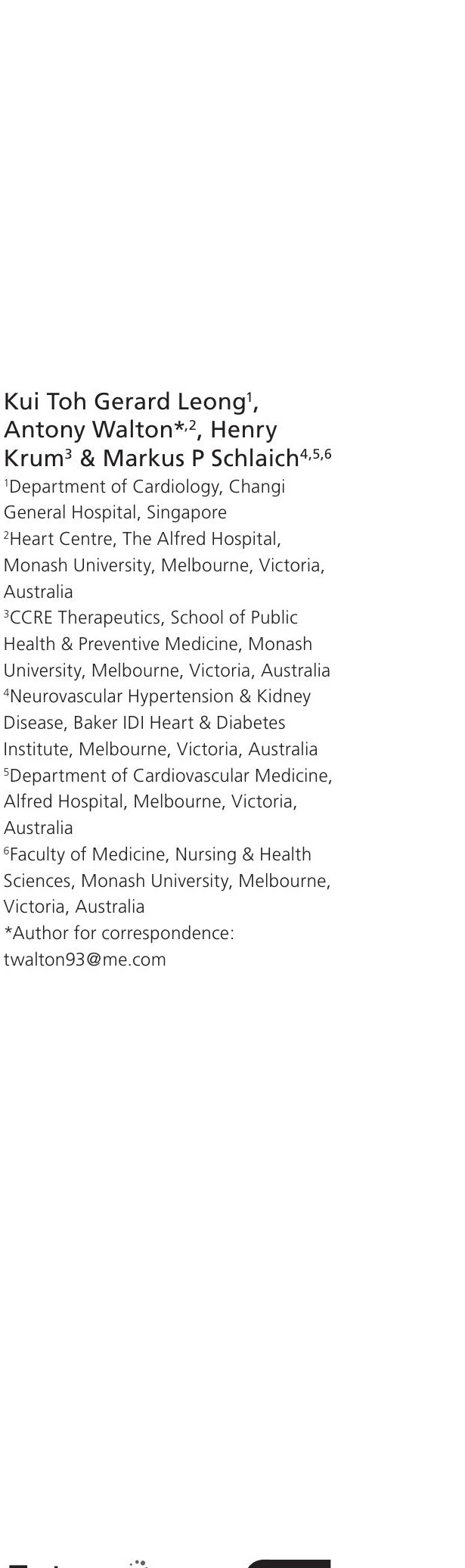

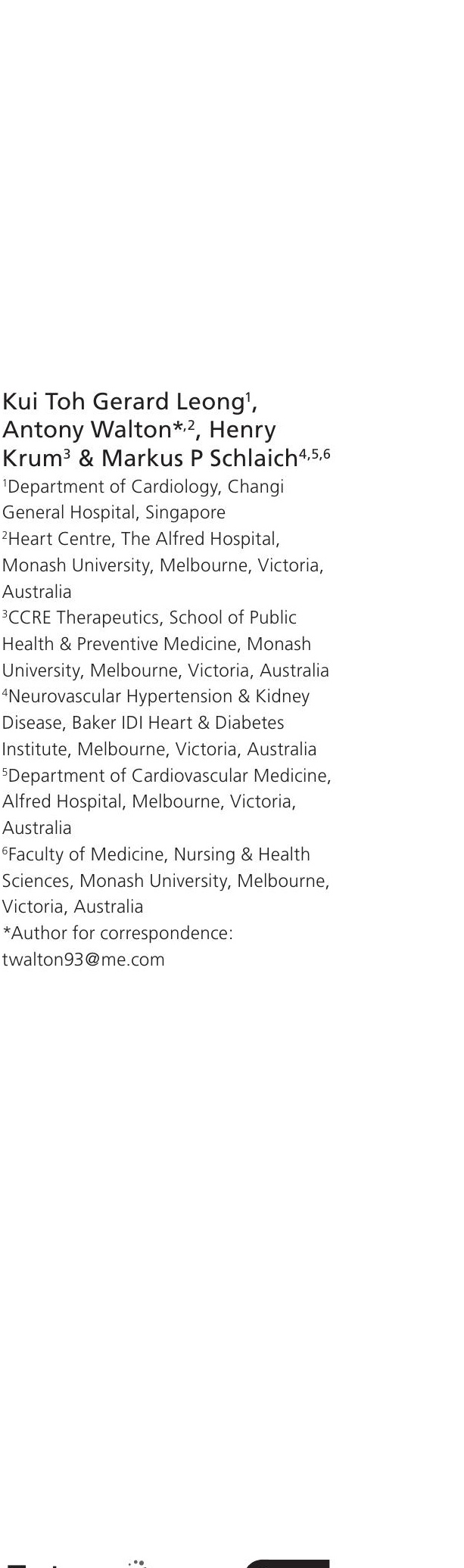

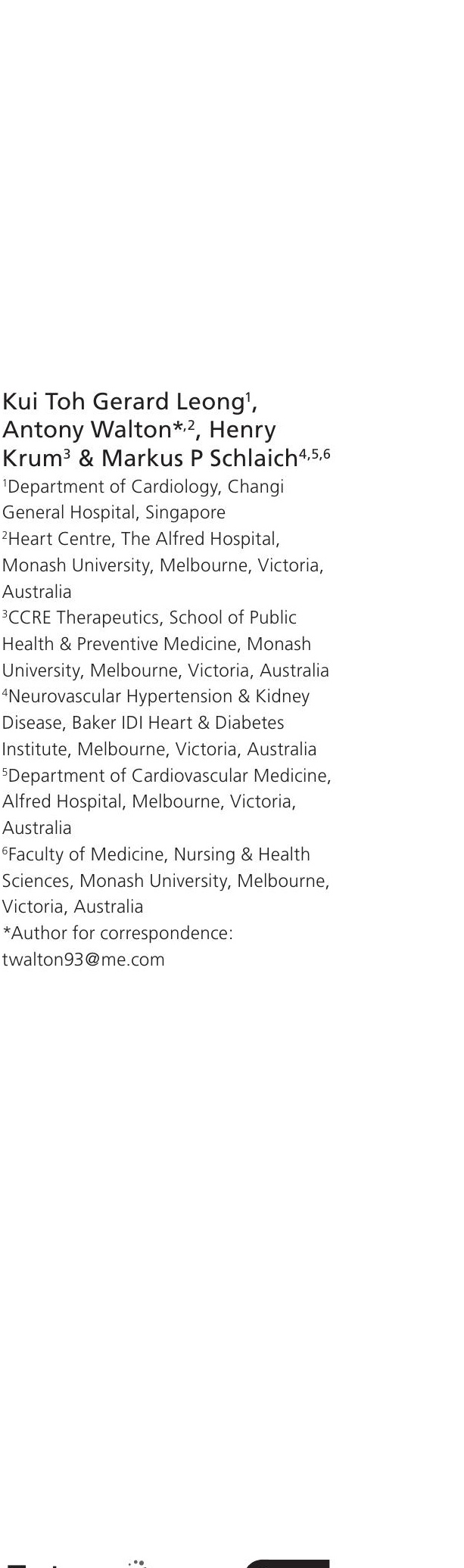

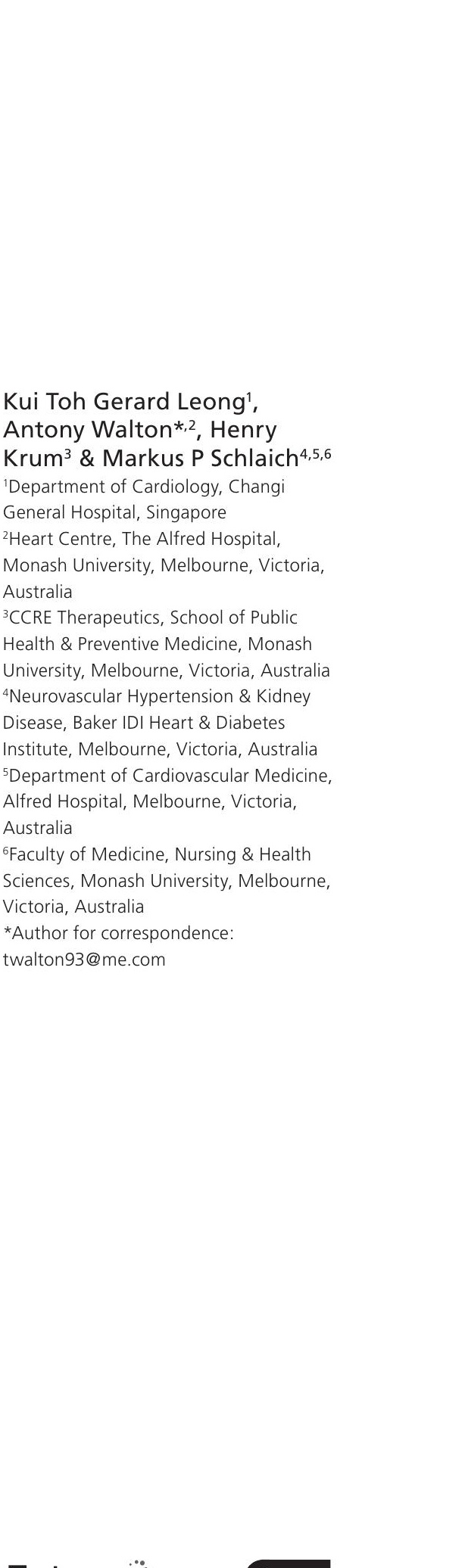

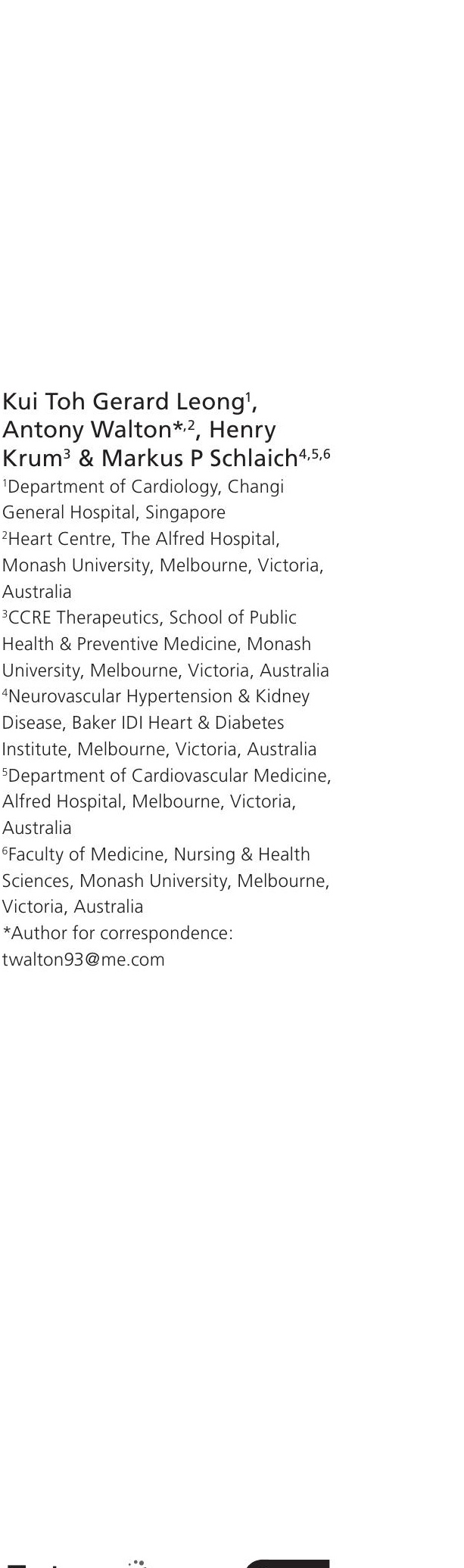

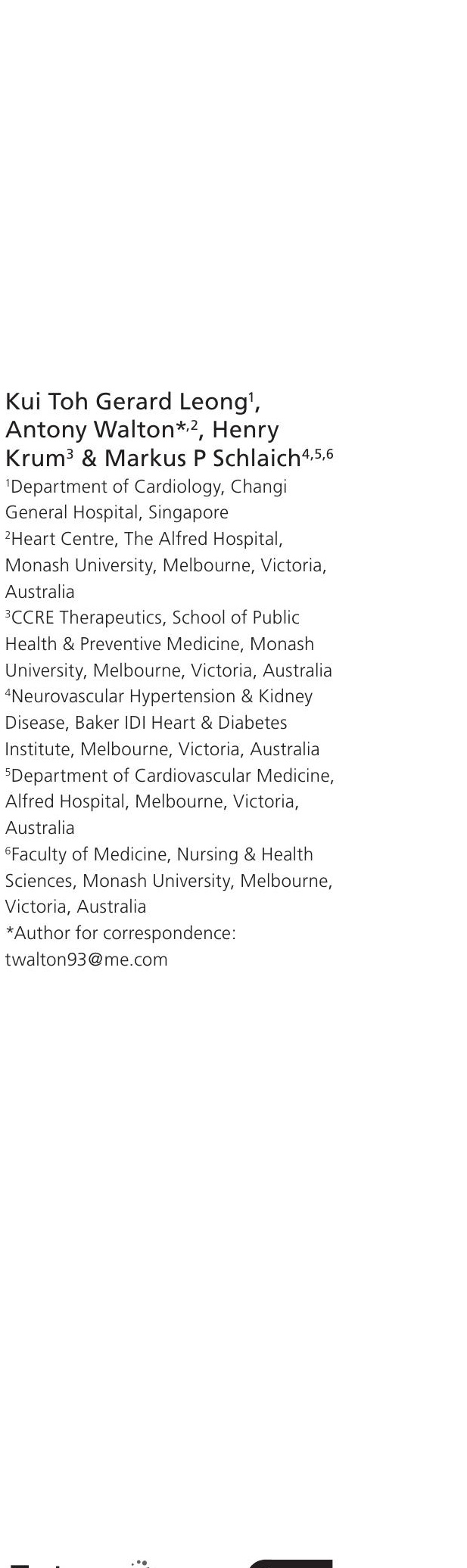

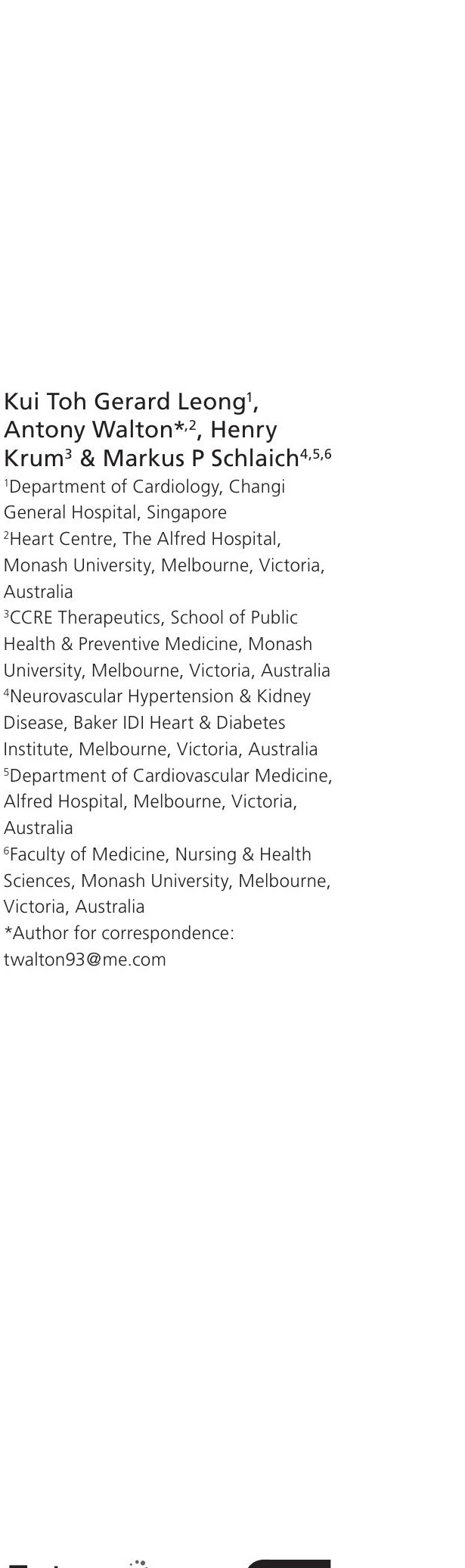

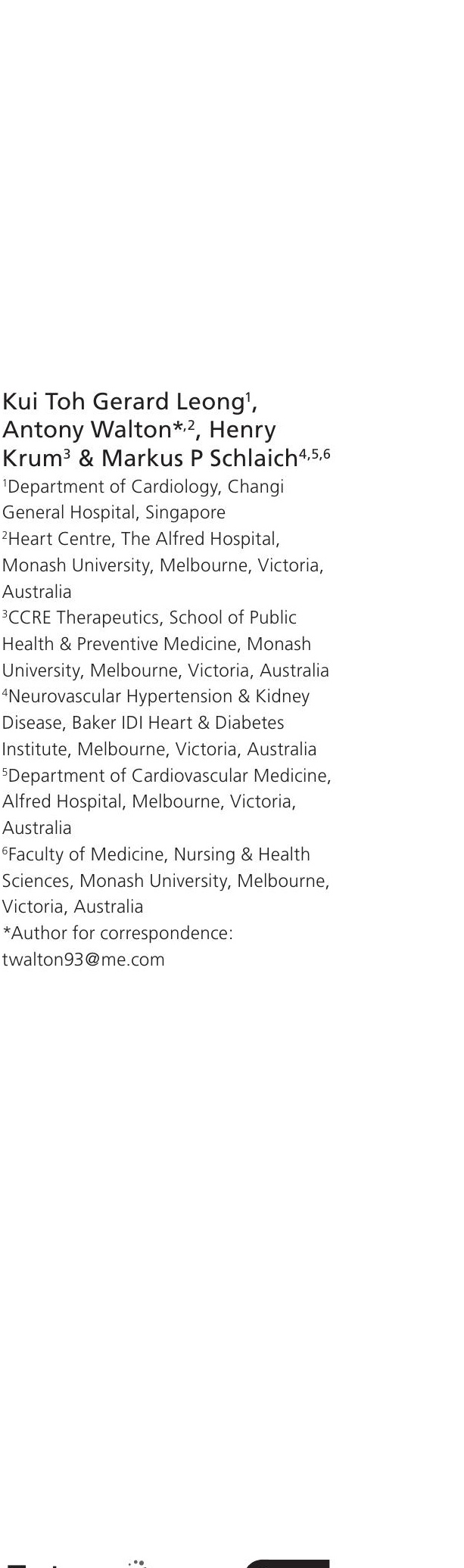

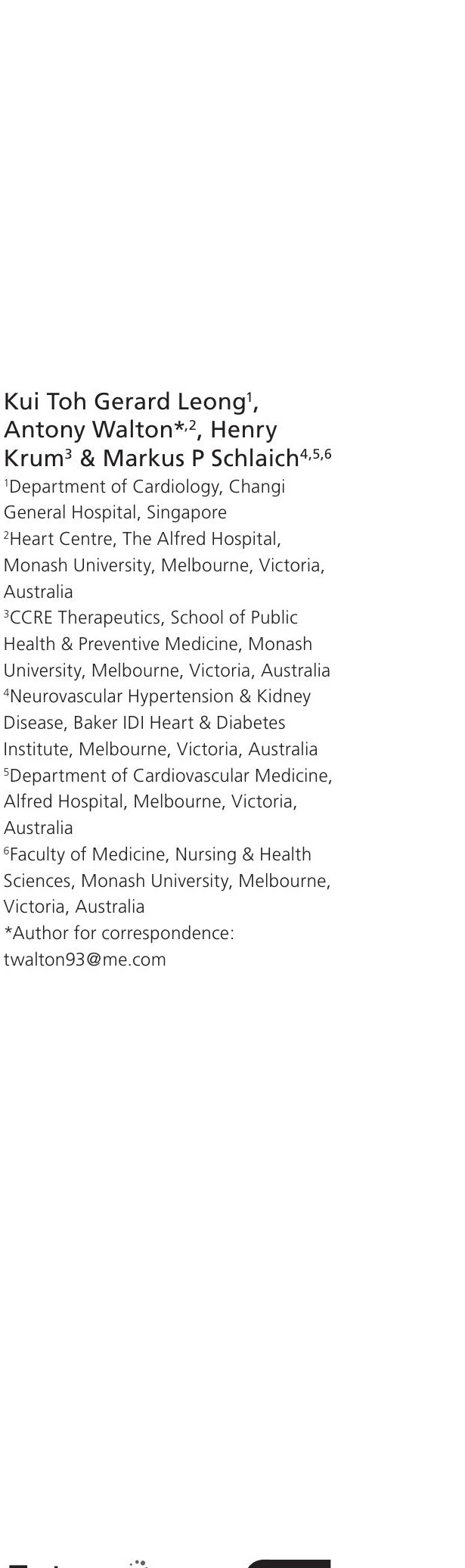

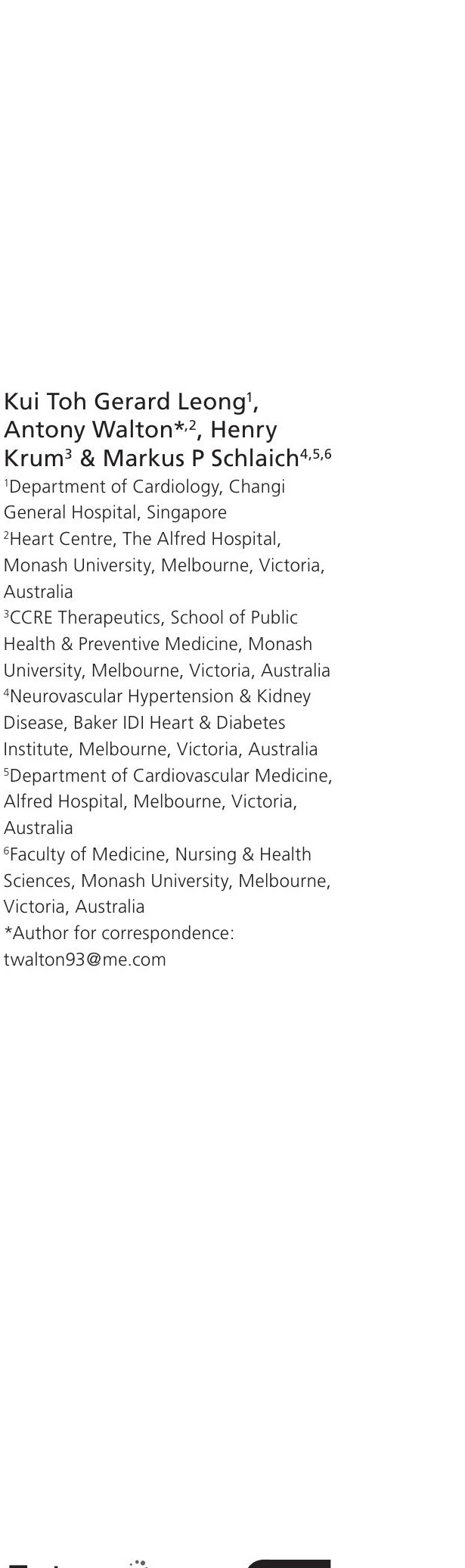

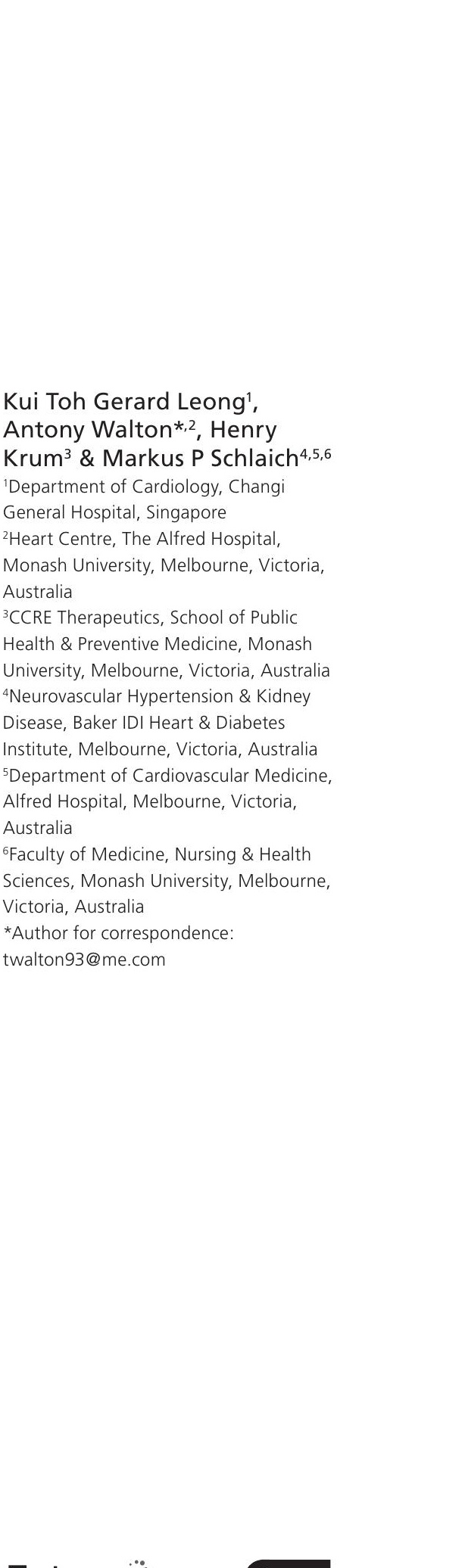

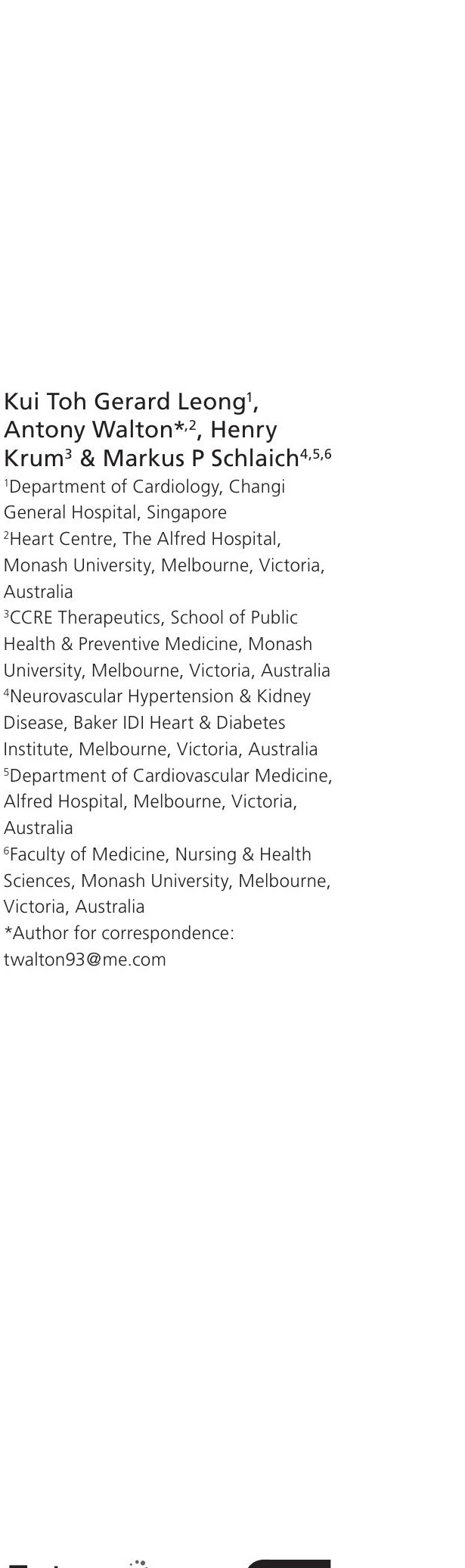

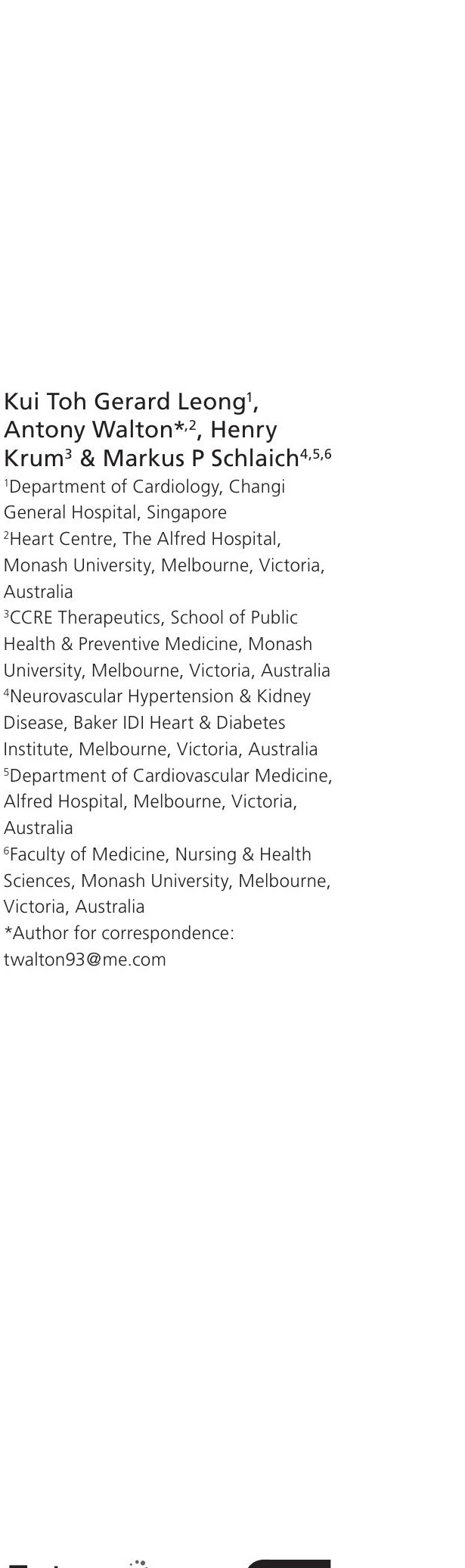

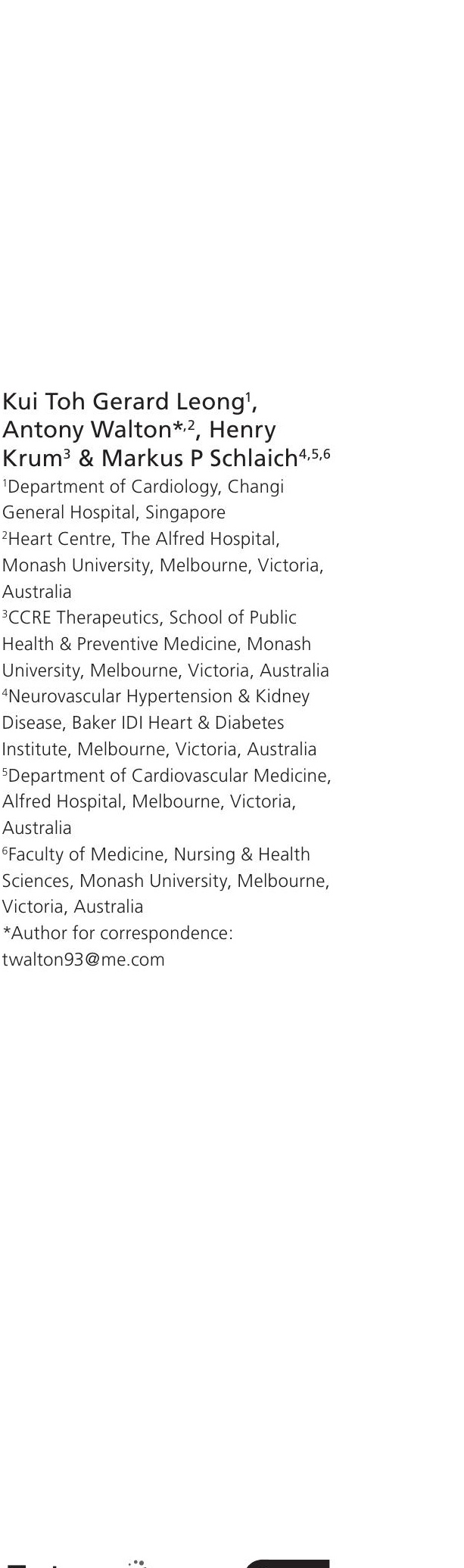

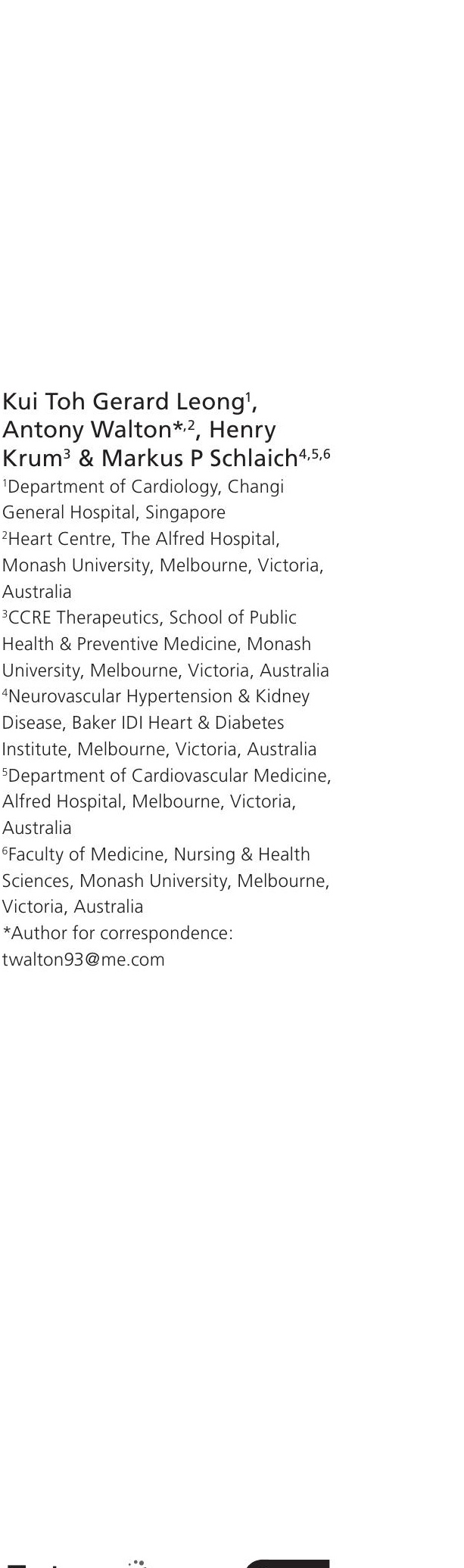

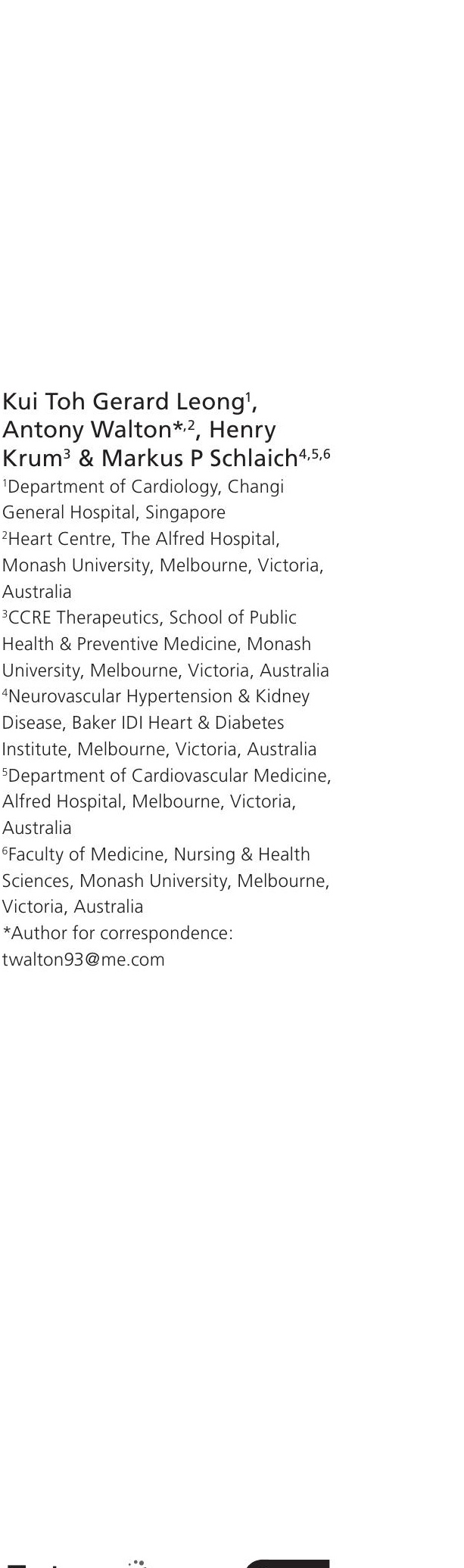

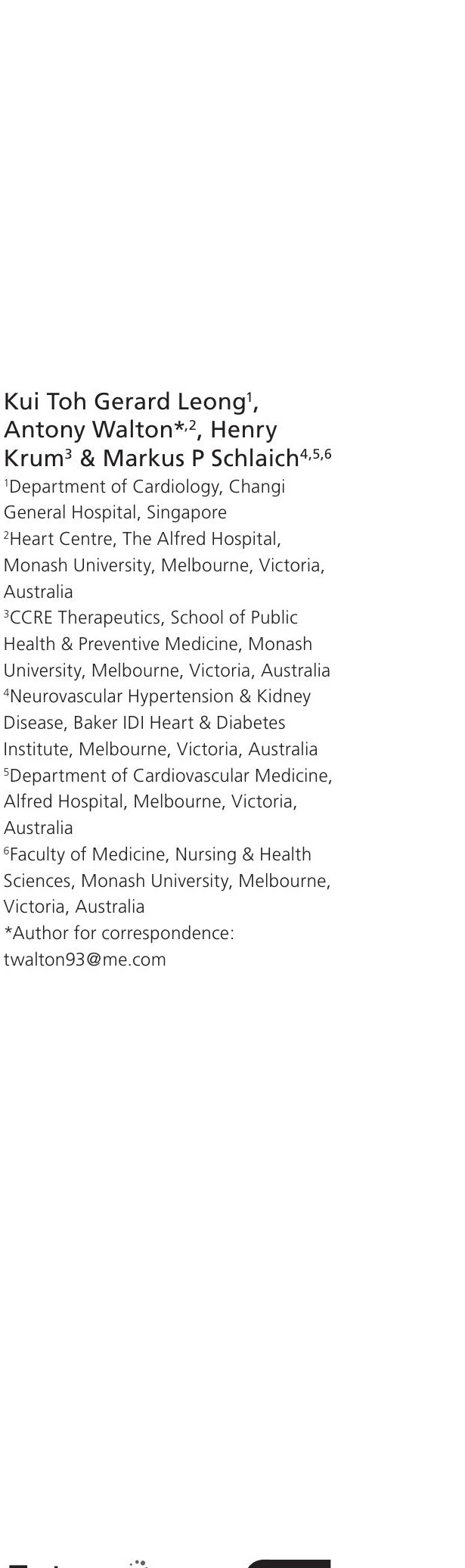

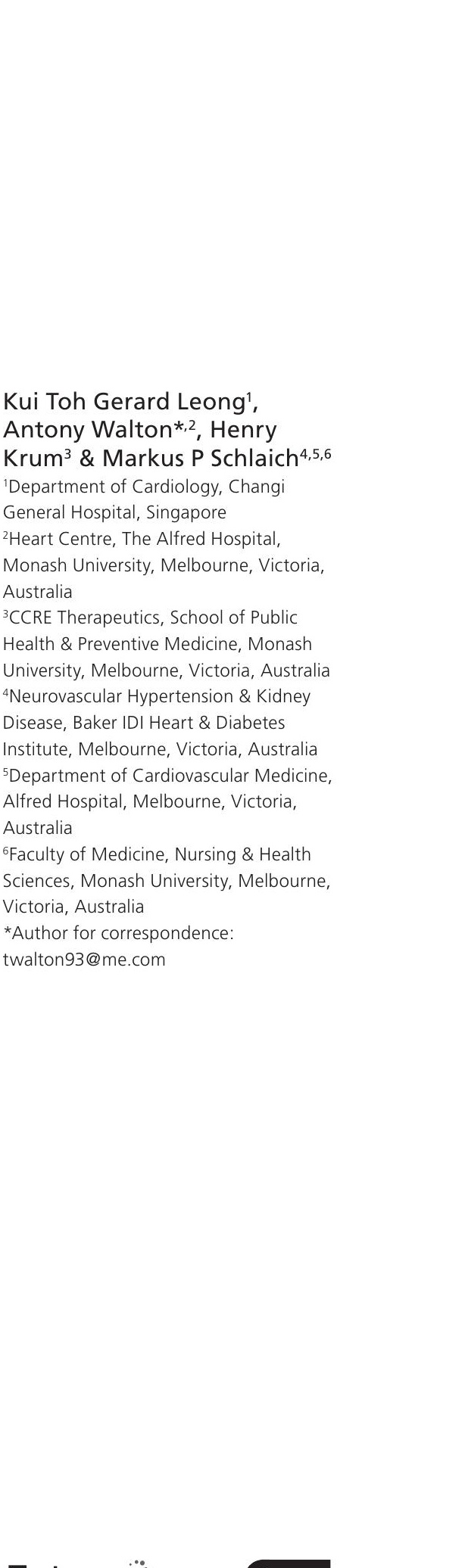

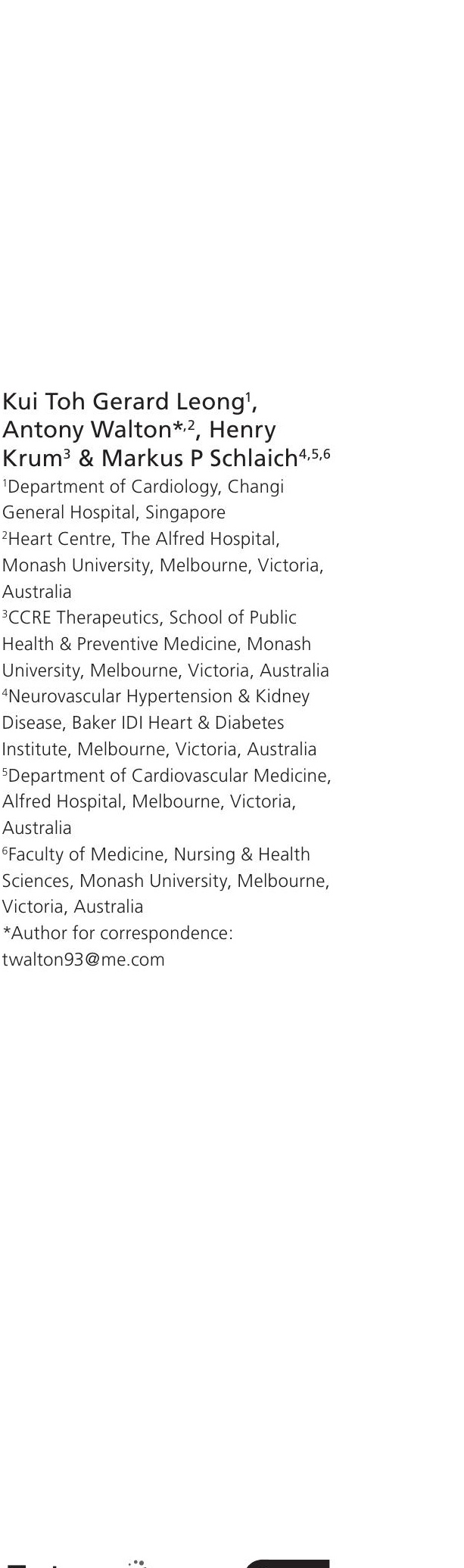

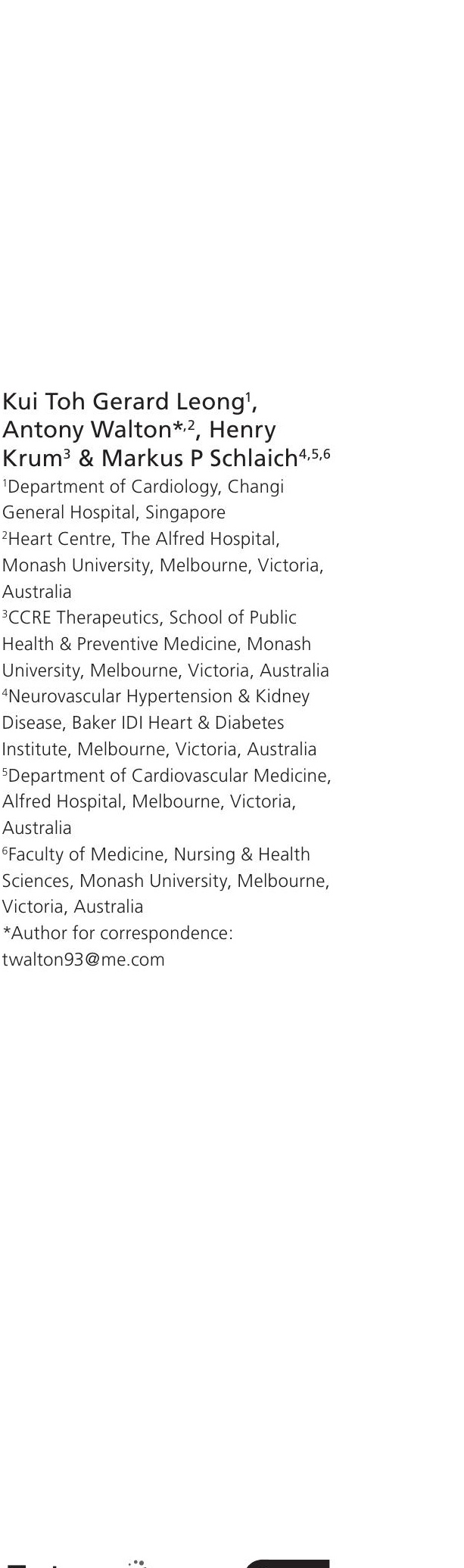

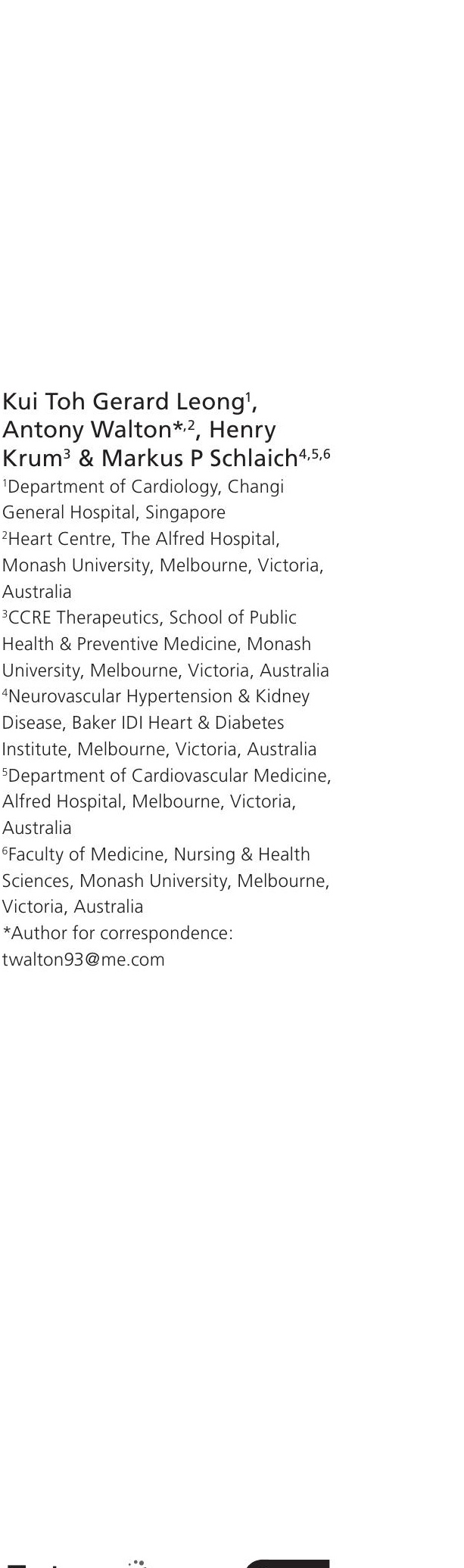

Future $\mathrm{fSS}$ 


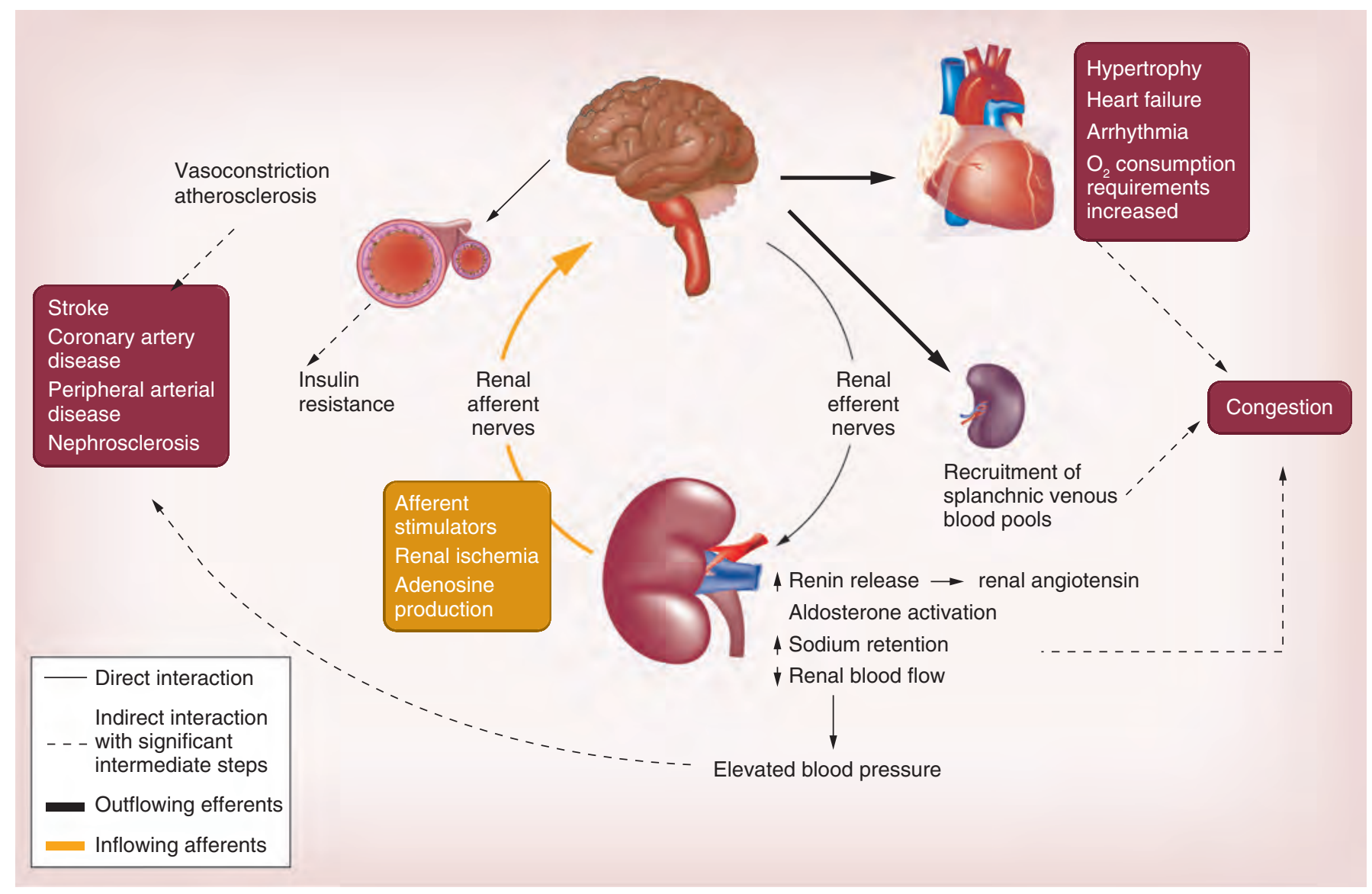

Figure 1. Representation of the sympathetic nervous system, demonstrating the complex interaction between afferent sensory signaling from the kidney and efferent sympathetic outflow to the kidney, and the multiple deleterious consequences of a hyperexcitatory sympathetic nervous state.

Adapted with permission from $[1,2]$.

guide catheter is recommended to reduce the risk of arterial spasm. A proprietary steerable radiofrequency (RF) ablation catheter connected to its generator is then inserted into the renal arteries under fluoroscopic guidance. Several discrete RF ablations (typically 4-8, depending on the individual renal artery anatomy) are then applied onto the renal artery wall. Each ablation lasts up to $2 \mathrm{~min}$, and is $8 \mathrm{~W}$ or less. These ablations are separated both longitudinally and rotationally within each renal artery. The catheter tip temperature and impedance are constantly monitored during ablation, with RF energy delivery regulated according to a predetermined algorithm. During the RF ablation,

\section{Box 1. Pathologies with hyperexcitatory}

\section{sympathetic nervous states.}

- Hypertension

- Heart failure

- Cardiac arrhythmia

- Kidney disease

- Sleep-disordered breathing

- Insulin resistance there is diffuse visceral nonradiating abdominal pain of varying intensity. This discomfort does not last beyond the RF energy application and can be managed safely with intravenous amnesic and narcotic sedatives.

With present experience, complications of percutaneous RSDN are not common. In the ongoing Global SYMPLICITY Registry, the analysis of the first 1000 cases that have been done, the major adverse event rate was $0.8 \%$. Potential complications of percutaneous RSDN include those pertaining to vascular (femoral artery) access, for example, bleeding, dissection, vasovagal response and those more specific to renal artery cannulation and denervation, for example, renal artery dissection, stenosis or impairment.

\section{Resistant hypertension}

In Europe, on the basis of the SYMPLICITY-1 [4] and -2 studies [5], which have shown RSDN to be safe and efficacious in blood pressure (BP) reduction (with ongoing efficacy sustained up to 36 months [6]), RSDN is an approved therapeutic option for resistant severe essential hypertension with no significant 
renal impairment (estimated glomerular filtration rate [eGFR]: $\geq 45 \mathrm{ml} / \mathrm{min} / 1.73 \mathrm{~m}^{2}$ ) and suitable renal artery anatomy. The European Society of Hypertension has released a position paper with strict eligibility criteria for RSDN [7]. In addition to the criteria in the SYMPLICITY-1 and -2 studies, this position paper emphasized that potential candidates for RSDN have a thorough clinical examination to confirm treatment resistance and to exclude both pseudoresistance and white-coat hypertension with use of home and 24-h ambulatory BP monitoring. It reinforced the need for close attention be placed on diagnosis and treatment of reversible causes of uncontrolled hypertension, including addressing compliance issues and removing iatrogenic causes. In the latest 2013 ESH/ESC Guidelines for the management of arterial hypertension [8], RSDN is described as a promising method for controlling resistant hypertension, but requiring more data from properly designed long-term comparison trials to conclusively establish its safety and persistent efficacy compared with the best possible drug treatments. It goes on to comment that understanding what makes renal denervation (RDN) effective or ineffective (patient characteristics or failure to achieve renal sympathectomy) will be important to choose the likely responders to this therapy.

However, the definitive proof of the therapeutic role of percutaneous RSDN in resistant hypertension has been thrown into doubt with the results from the SYMPLICITY HTN-3 study [9]. This is the first prospective, single-blind, randomized, sham-controlled trial, where patients with severe resistant hypertension (confirmed with 24-h ambulatory BP), only achieved its 6-month safety (major adverse events in RSDN vs sham-procedure arms were 1.4 vs $0.6 \%$; $=0.67$ ) but not its efficacy end points of significant difference in change in office systolic BP (SBP) and mean 24-h ambulatory SBP between RSDN and sham procedure $(-2.39 \mathrm{mmHg}, \mathrm{p}=0.26$ and $-1.96 \mathrm{mmHg}, \mathrm{p}=0.9$, respectively) at 6 months.

However, within each group, there was a significant change from baseline to 6 months in office SBP $(-14.13 \pm 23.91, \mathrm{p}<0.001$ in the RSDN group; $-11.74 \pm 25.94 \mathrm{mmHg}, \mathrm{p}<0.001$ in the sham-procedure group). There was also a significant change from baseline to 6 months in ambulatory $24-\mathrm{h}$ average SBP observed in both groups $(-6.75 \pm 15.11 \mathrm{mmHg}, \mathrm{p}<0.001$ in the RSDN group; and $-4.79 \pm 17.25 \mathrm{mmHg}, \mathrm{p}<0.001$ in the sham-procedure group).

The proportions of patients with a reduction in office systolic or diastolic BP of at least $5 \mathrm{mmHg}(66.9$ vs $55.6 \% ; \mathrm{p}=0.02)$ or at least $10 \mathrm{mmHg}$ (58.3 vs $48.5 \% ; \mathrm{p}=0.04)$ were also significantly greater in the RSDN group than in the sham-procedure group.
Prespecified subgroup analysis has revealed several findings. It has shown that the non-African-American cohort benefited more from RSDN than the African-American cohort with significant betweenprocedure group difference in change in office SBP (-6.63 $\mathrm{mmHg}$; 95\% CI: -11.81 to $-1.44 ; \mathrm{p}=0.01)$. It was also revealed that patients with eGFR $\geq 60 \mathrm{ml} / \mathrm{min} / 1.73 \mathrm{~m}^{2}$ (-5.22; 95\% CI: -10.51-0.06; $\mathrm{p}=0.05)$ and patients less than 65 years $(-5.73 \mathrm{mmHg}$; 95\% CI: -11.06 to $-0.40 ; \mathrm{p}=0.04)$ may benefit from RDSN. These findings behooves further studies as the trial was underpowered to detect small differences in systolic or diastolic BP or any potential effects in subgroups.

In the SYMPLICITY HTN-3 study, there was intense medical therapy. In the RSDN and shamprocedure arms of the study, the mean ( \pm standard deviation) number of antihypertension agents were $5.1 \pm 1.4$ and $5.2 \pm 1.4$, respectively, of which the mean maximally tolerated antihypertension agents were $4.0 \pm 1.1$ and $4.0 \pm 1.0$, respectively. Interestingly, about 85 and $45 \%$ on both arms were on $\beta$-blockers and centrally acting sympatholytics, respectively. Multivariate analysis revealed that multidosing (up to $4 \times$ per day) vasodilators were more commonly administered in the sham-procedure arm of the African-American population, as well as in non-African-American patients who did not achieve a significant response.

\section{What can possibly account for SYMPLICITY HTN-3 study efficacy results, which differ from the previous SYMPLICITY HTN-1 \& -2 trials?}

Compared with SYMPLICITY HTN-1 and -2 trials, in the SYMPLICITY HTN-3 study, enrolled patients required 24-h ambulatory BP to confirm eligibility, and the patients had to be on the maximum-tolerated medication dosage. The population studied was more heterogeneous. The number of trial sites and operators were much larger, and the operators RSDN experience lower (3.3 procedures per operator in SYMPLICITY HTN-3 compared with 6 procedures per operator in SYMPLICITY HTN-1), all of which may have led to greater procedural variability, and inadequate denervation. The Hawthorne effect [10] could account for the improved outcomes in the sham-procedure arm, thus diminishing the difference in efficacy between the two study arms in SYMPLICITY HTN-3.

The 6-month period from baseline to determination of the primary end point might be premature to definitively decree that the RSDN procedure is a failure in resistant hypertension. If RSDN truly works in resistant hypertension, the drop in SBP in the RSDN arm will persist while that of the sham-procedure arm 
degrades with time, as patient compliance to polypharmacy diminishes and the Hawthorne and placebo effects wane.

It is also very possible that SYMPLICITY HTN-3 is a true result and that RSDN does not work in resistant hypertension. However, it is the authors' experience and opinion that it is effective for selected resistant hypertension patients. The challenge is to identify which subgroups are likely to benefit the most.

The results from SYMPLICITY HTN-3 study is in contrast from the results announced at the American College of Cardiology/i2 Scientific Session in Washington, DC, USA on 30 March 2014, of the 6-month analysis of the first 1000 (of the planned 5000) patients with uncontrolled hypertension who were treated with Symplicity Catheter System (Medtronic, CA, USA) in a real-world multinational observational Global SYMPLICITY Registry [11].

The safety profile of RSDN was reiterated in SYMPLICITY HTN-3 study. Even in the hands of less experienced operators in SYMPLICITY HTN-3, the major adverse event rate was $1.4 \%$ in the RSDN arm and $0.6 \%$ in the sham-procedure arm. As for efficacy, of all patients available for 6-month follow-up, overall office SBP reduction was $11.9 \mathrm{mmHg}(\mathrm{n}=751)$ and $24-\mathrm{h}$ ambulatory SBP reduction was $7.9 \mathrm{mmHg}$ ( $\mathrm{n}=404$ ). For patients with office $\mathrm{BP} \geq 160 \mathrm{mmHg}$ and ambulatory $\mathrm{BP} \geq 135 \mathrm{mmHg}$ at baseline receiving greater $\geq 3$ antihypertensive medication classes, they had a SBP reduction of $20.2 \mathrm{mmHg}$ at 6 months $(\mathrm{n}=244)$.

The European Society of Hypertension (ESH) has released a statement [12] following the SYMPLICITY HTN-3 trial, stating that the conclusion that RSDN is ineffective is not justified. It goes on to say that based on the rationale of RSDN therapy in resistant hypertension and existing background preliminary data, the reaction to the negative results of the SYMPLICITY HTN-3 study should not be to prematurely abandon the RSDN approach, but to perform more highquality studies to further elucidate the role of RSDN in resistant hypertension, especially whether specific patient groups might benefit from RSDN therapy. This is important as there is a significant unmet therapeutic need in patients with poorly controlled resistant hypertension despite existing pharmacological therapy.

With regard to RSDN's therapeutic role in resistant hypertension, the existing data are less than 5 years old, and clinical outcomes data are lacking. Longerterm safety, effectiveness and clinical outcomes data on already concluded trials need to be collected and analyzed.

Larger-scale, prospective, randomized, blinded clinical outcome trials with different patient groups are needed. We need to find out which patient group will benefit most, as there is a significant unmet therapeutic need in patients with poorly controlled resistant hypertension despite existing pharmacological therapy.

\section{Heart failure}

Heart failure (HF) is a chronic condition that exerts a high disease burden for the individual and the community [13]. It shares with hypertension, a common pathophysiology in the detrimental hyperexcitation of the cardiovascular sympathetic drive [14,15].

There have been numerous studies demonstrating the role of hyperactivation of the SNS in reduced ejection fraction HF (REFHF) and in the cardiorenal syndrome $[16,17]$ and its association with increased mortality [18-20]. It has also been demonstrated elegantly by Petersson et al. [21] that renal noradrenergic activation has a strong negative predictive value on outcome in REFHF independent of overall sympathetic activity, GFR and left ventricle ejection fraction (LVEF). From these findings, the authors suggested that treatment regimens that further reduce renal noradrenergic stimulation could be advantageous by improving survival in patients with HF.

Indirect evidence for the potential benefit of RSDN in HF is from the established clinical and cardiac remodeling benefits of inhibiting the SNS and renin-angiotensin-aldosterone systems by pharmacological means [22]. However, one notable trial of an oral central sympathetic inhibitor, moxonidine sinus rhythm (SR) in REFHF was disappointing. The MOXCON study [23] was terminated early due to excess short-term mortality and morbidity in the moxonidine SR therapy arm. The authors' interpretation was that the early termination of the trial limited conclusions regarding the long-term effects of central sympathetic inhibition. Nonetheless, the excess early mortality and morbidity suggested the likelihood of an adverse effect of moxonidine SR and raised concerns regarding the efficacy of generalized sympathetic inhibition in HF. This could prove that the premise of central sympathetic inhibition in REFHF is wrong or it could have been due to excessive and too rapid nonselective sympathetic inhibition with this agent. This also suggests that organ-selective blockade of the SNS may offer greater promise, and selective denervation of the renal arteries may provide more complete and specific blockade of renal sympathetic traffic than any combination of central systemically sympatholytic agents, while avoiding unwanted multi-organ side effects from profound global SNS inhibition.

There have been several animal studies showing the benefit of surgical RSDN in coronary artery ligation or pacing induced REFHF in terms of reduced ventricular 
filling pressures, improved ventricular function, and renal salt and volume homeostasis [24-26]. These animal studies suggest that RSDN may be particularly useful in the treatment of HF in patients.

A first-in-man experience investigating RSDN in HF was recently published, suggesting the safety of the procedure in patients with REFHF [27]. There are now numerous ongoing trials on the therapeutic use of RSDN in REFHF.

The Renal Denervation in Patients With Chronic Heart Failure \& Renal Impairment clinical trial (SYMPLICITY HF, NCT01392196) is an ongoing prospective trial of RSDN in patients with symptomatic (New York Heart Association functional class II and above) systolic HF (a LVEF less than 40\%) and moderately preserved renal function (eGFR: $\geq 30-35 \mathrm{ml} / \mathrm{min} / 1.73 \mathrm{~m}^{2}$ ). The results may further answer the important question whether RSDN is safe and effective in systolic HF. In SYMPLICITY HF, cardiac function and/or renal physiological responses to RSDN are being studied. A subset will be analyzed for intracardiac pressures (right-heart catheterization), cardiac and renal norepinephrine spillover, heart-rate variability and arrhythmias (Holter monitoring), muscle sympathetic-nerve activity and renal blood flow (MAG3 imaging).

The Renal Artery Denervation in Chronic Heart Failure study (REACH, NCT01639378) is a prospective, double-blinded, randomized, controlled safety and effectiveness study of RSDN in REFHF. This ongoing study will focus on symptoms of HF and ventilatory responses to exercise and chemoreceptor stimulation. This study will include assessments of symptom status, slope of ventilation to $\mathrm{CO}_{2}$ production $\left(\mathrm{VE} / \mathrm{VCO}_{2}\right.$ slope) on exercise chemoreflex sensitivity, arrhythmia burden and ambulatory BP.

Study of RDN in patients with HF (PRESERVE, NCT01954160) is an ongoing Phase II, randomized, open-labeled trial, with the primary purpose of assessing the effect of RSDN on urine sodium excretion in symptomatic (NYHA II or III) patients with REFHF (LVEF $\leq 40 \%$ ). Secondary outcome measures include clinical, cardiac echocardiographic, biochemical markers and renal function. Hypertension is not an inclusion or exclusion criteria, though orthostatic hypotension or known dysautonomia is. Orthostatic hypotension is defined by $\geq 1$ of the following feature(s) within 2-5 min of quiet standing: $\geq 20 \mathrm{mmHg}$ fall in systolic pressure or $\geq 10 \mathrm{mmHg}$ fall in diastolic pressure.

As there is a proven role of SNS hyperactivation in $\mathrm{HF}$, and possible role in the pathophysiology of fluid congestion, and dyspnea, both hallmarks of heart failure with preserved ejection fraction (HFPEF), there may be a potential therapeutic role for RSDN in HFPEF. This potential therapeutic role is being actively evaluated.

The denervation of the renal sympathetic nerves in HF with normal LV ejection fraction (DIASTOLE) study [28] is a Phase II, randomized, controlled openlabeled single-center Dutch trial, evaluating RSDN as a treatment option for patients with HFPEF and primary hypertension. It will investigate whether RSDN influences echocardiographic, cardiac MRI, clinical and biochemical parameters of heart failure with normal ejection fraction.

The RESPECT HF (NCT02041130) is an international Phase II trial, involving centers in Australia, New Zealand and Singapore. It is a randomized, controlled, open-labeled trial assessing the efficacy of RSDN therapy on echocardiographic, cardiac MRI, clinical and biochemical parameters of patients with HFPEF. Hypertension is not an inclusion criteria, though for safety reasons, SBP $<105 \mathrm{mmHg}$ is an exclusion criteria.

In patients with HF, elevated heart rate is directly related to mortality and morbidity [29] and heart-rate reduction is associated with improved outcomes [30,31]. Dysrhythmia in the form of atrial fibrillation (AF) and ventricular arrhythmias are common in $\mathrm{HF}$, and impose significant mortality and morbidity burden. Both atrial and ventricular arrhythmias are associated with sympathetic hyperactivity in HF [32,33] and the ventricular response rate in AF is often an expression of the sympathetic state. However, heart rate remains increased in most patients despite contemporary treatment with $\beta$-blockers [34]. This constitutes a further reason to seek new therapeutic approaches. RSDN may be a useful strategy to reduce electrophysiological events in HF.

\section{Cardiac arrhythmias}

The autonomic nervous system plays a relevant role in the onset, maintenance and interruption of ventricular arrhythmias [35]. In general, sympathetic activity facilitates ventricular arrhythmias, whereas vagal tone normally suppresses them. The shortening of effective ventricular refractory period, thereby allowing re-entry circuits, increased ventricular automaticity, and reduction of the threshold for ventricular arrhythmias are regarded as potential mechanisms of arrhythmogenesis by elevated sympathetic tone [36]. It has been observed that left stellate cardiac ganglionectomy results in both reduction of heart rate and shortening of the QT interval [37]. These observations give us reasonable assumption that RSDN may have a beneficial impact on ventricular arrhythmia management, in particular in patients with comorbidities such as hypertension, diabetes, coronary artery disease and myocardial infarction, where an autonomic imbalance leads to a higher risk of ventricular arrhythmias [38]. 
Ukena et al. has pried open the potential role of RSDN for the treatment of cardiac arrhythmias in a recent review article [39]. They reason that as the autonomic nervous system plays a pivotal role in the pathogenesis and maintenance of atrial and ventricular arrhythmias; renal afferent nerves are regulators of central sympathetic tone, and catheter-based RSDN is associated with a reduction of central sympathetic activity, muscle sympathetic nerve activity (MSNA) and BP in resistant hypertension. There is a reasonable possibility of RSDN being able to modulate sympathetic activity, without affecting peripheral chemoreceptors and mechanoreceptors in the heart and other organs. RSDN was shown to reduce heart rate in humans and to reduce inducibility of AF as well as ventricular rate during AF in experimental studies. First evidence indicates that pulmonary vein isolation (PVI) in combination with RDN increases the rate of AF freedom in patients with resistant hypertension. Furthermore, RSDN may have a beneficial impact on ventricular arrhythmia, in particular in patients with coronary artery disease or HF. The first clinical evidence came from Pokushalov et al. [40] investigating the additive effect of RSDN in patients with symptomatic AF and resistant hypertension undergoing PVI. In this study, 27 patients were enrolled and randomized to either PVI alone or PVI in combination with RSDN. Besides a significant reduction of SBP (from 181 to $156 \mathrm{mmHg}$; < 0.001) the rate of AF freedom at 12 months was also significantly higher in the PVI + RDN group (69 vs 29\%; p = 0.033) compared with PVI alone.

Ukena et al. also recently reported treatment of electrical storm by RDN in two patients as first-in-man experience [41]. Both patients had symptomatic HF (NYHA class III) and suffered from recurrent episodes of ventricular arrhythmias. Cardiac ablation therapies failed or were declined, therefore RSDN was performed as an experimental attempt to reduce ventricular arrhythmia burden. In both cases, RSDN did not result in any apparent acute or chronic hemodynamic complications in these normotensive patients. Ventricular arrhythmias were markedly reduced in both patients following the procedure. As sympathetic activity was not measured directly, the efficacy of RDN was indirectly observed via an improvement of the glycemic status of one patient with diabetes. Further studies investigating RDN for treatment of ventricular arrhythmias and electric storm are necessary and ongoing.

\section{Renal disease}

There is heightened sympathetic tone in patients with chronic kidney disease, but the exact mechanisms contributing to this remain unclear [42]. In a study by Zoccali et al. [43], a cohort of 228 end stage renal disease patients undergoing chronic hemodialysis who did not have HF at baseline and who had LVEF greater than $35 \%$ was studied for the association between sympathetic nerve overactivity (as indicated by an elevated plasma concentration of norepinephrine) and clinical outcomes. It was observed that sympathetic nerve overactivity was found to be an independent predictor of fatal and nonfatal cardiovascular outcomes in end stage renal disease.

Animal studies [44] have pointed to the potential reno-protective effects of pharmacological sympatholytic agents, independent of BP-lowering effect. In humans, centrally acting sympatholytic agents, such as moxonidine, have been shown to delay the progression of renal failure and reduced MSNA in normotensive patients with Type I diabetes mellitus, in the absence of BP changes [45-47].

It has also been shown that there may be a role for percutaneous RSDN in the treatment of hypertensive nephropathy. A pilot study has shown this procedure to be safe and efficacious in patients with resistant hypertension and moderate to severe chronic renal impairment [48]. In this pioneering study, bilateral RSDN was performed in 15 patients with resistant hypertension and stage 3-4 chronic kidney disease (mean eGFR: $31 \mathrm{ml} / \mathrm{min} / 1.73 \mathrm{~m}^{2}$ ). $\mathrm{CO}_{2}$ angiography was used in six patients to minimize contrast nephropathy. eGFR remained unchanged after the procedure, regardless of the use of $\mathrm{CO}_{2}$ angiography. Mean baseline $\mathrm{BP}$ was $174 \pm 22 / 91 \pm 16 \mathrm{mmHg}$ despite the use of $5.6 \pm 1.3$ antihypertensive drugs. Mean changes in office systolic and diastolic BP at 1, 3, 6 and 12 months were $-34 /-14$, $-25 /-11,-32 /-15$ and $-33 /-19 \mathrm{mmHg}$, respectively. Night-time ambulatory BP was significantly decreased $(\mathrm{p}<0.05)$, restoring a more physiologic dipping pattern.

In an animal study by Luippold et al. [49], Sprague-Dawley rats were subjected to bilateral RDN before induction of diabetes mellitus (DM) by streptozotocin. Clearance experiments were performed 2 weeks after onset of moderate DM. Glomerular volume was estimated following paraformaldehyde fixation in rat kidney slices from measurement of crosssectional area of Bowman's capsule. It was shown that renal nerves appeared to be significantly involved in the mediation of glomerular hyperfiltration in experimental DM, and observed that if the kidney is prevented from sympathetic nerve stimulation, structural changes due to early diabetic nephropathy, in other words, glomerular enlargement, were abolished.

Increased renal resistive index [50] and urinary albumin excretion are markers of hypertensive endorgan damage and renal vasoconstriction consequent of increased sympathetic activity. In a prospective nonrandomized observational study, RSDN safely 
and effectively reduced $\mathrm{BP}$, renal resistive index and incidence of micro- and macro-albuminuria without adversely affecting GFR or renal artery structure while significantly reducing $\mathrm{BP}$ in patients with resistant hypertension within 6 months [51]. Whether this reduction in incidence of albuminuria is due to better BP control or is directly via reduced sympathetic tone will require further studies.

These above studies highlight the potential application of percutaneous RSD to the treatment of kidney disease even without hypertension. More studies will be required regarding this potential therapeutic indication.

\section{Sleep-disordered breathing}

Sleep-disordered breathing in the form of obstructive sleep apnea (OSA) is highly prevalent in patients with resistant hypertension, affecting up to $80 \%$ of these patients. It is an etiology in resistant hypertension [52]. It is also independently associated with an increased risk of cardiovascular events [53]. Patients with OSA have been observed to have elevated MSNA [54], which is reduced following adequate treatment of the obstruction. There is a pilot observational study that shows that catheter-based RSDN lowered BP in patients with refractory hypertension and OSA, and this was accompanied by improvement of sleep apnea severity [55]. This study will reveal the potential role of percutaneous RSDN in the treatment of sleep apnea with or without hypertension.

\section{Insulin resistance}

Sympathetic overactivity has been observed with obesity, insulin resistance [56] and the metabolic syndrome [57]. Approximately $50 \%$ of patients with essential hypertension have insulin resistance [58]. Mahfoud et al. have observed that patients with resistant hypertension who had undergone RSDN have exhibited improvements in glucose metabolism with reduced insulin resistance [59]. They suggest that improved peripheral skeletal muscle microcirculation and glucose uptake, together with decrease in glucagon secretion and gluconeogenesis and reduced activity of the renin-angiotensin-aldosterone system may be the reasons for the beneficial effects of RSDN on glucose metabolism and insulin resistance. RSDN may reduce the progression from impaired glucose tolerance to frank DM, or, in some cases, may reverse underlying DM.

In another study of the effects of RSDN on hemodynamic, metabolic and renal parameters in two obese polycystic ovary syndrome patients with hypertension [60], where SNS activity was assessed at baseline using microneurography and norepinephrine spillover mea- surements, and insulin sensitivity was assessed with euglycemic hyperinsulinemic clamp, it was demonstrated that post-RSDN, there was an reduction of sympathetic nerve activity and improved insulin sensitivity, in the absence of weight change at 3-month follow-up. Glomerular hyperfiltration and urinary albumin excretion were also reduced.

These studies suggest that percutaneous RSD may represent a useful nonpharmaceutical approach for treating insulin resistance with or without drug-resistant hypertension

\section{Conclusion}

Much is known of the role of hypersympathetic states in the pathophysiology of multiple highly prevalent disease states. Percutaneous RSDN is a novel minimally invasive procedure, without the need for permanent device implantation. It has generated much excitement in the treatment of resistant hypertension. With present experience, it appears to be a safe procedure based on the sound principle of breaking of the hypersympathetic activation states at the level of the kidney. While its therapeutic role in the treatment of resistant hypertension still requires definitive proof, there are still multiple exciting future potential indications for its use. This behooves us to dwell more into such research.

\section{Future perspective}

From existing trials and real-world experience, percutaneous RSDN is shown to be safe. This makes it easier for future evaluation of its different potential clinical uses. There are already numerous studies as outlined above in this endeavor. Its role in resistant hypertension and HF and other diseased states needs to be further clarified, with potential responder patient groups identified. At the moment, there are no peri-procedural tests or markers to predict the potential response status. More studies are needed into this area.

As technology advances, we are already seeing and very likely to see more new RSDN systems, with faster and/or safer alternative modes of energy delivery, for example, Medtronic Multi-Electrode Radiofrequency System, which allows for simultaneous application of ablation energy at multiple different points in the renal artery lumen to denervate the renal sympathetic nerves. This allows for shorter procedure time and lower contrast dose per procedure; or Kona Medical externally focused ultrasound therapy, which does not even require arterial access.

RSDN via radial access is already available with Terumo Iberis RSDN System. This allows for less patient discomfort and patients may be discharged from the hospital earlier. 
Executive summary

\section{Background}

- The human sympathetic nervous system (SNS) has an important regulatory role. In its dysfunctional hyperexcitatory state, it can lead to multiple pathologies.

- The renal sympathetic nerves play a significant role in these pathological states.

Rationale for \& description of percutaneous renal sympathetic denervation

- The rationale for percutaneous renal sympathetic denervation (RSDN) lies in the interruption of the excitatory renal sympathetic impact on the target organs. It allows for safe minimally invasive selective denervation of the renal sympathetic nerves.

- A brief description of the procedure is provided.

Resistant hypertension

- RSDN has been shown to be safe and efficacious in blood pressure reduction in earlier nonblinded SYMPLICITY HTN-1 and -2 trials.

- In Europe, it is an approved for a select group of truly resistant severe essential hypertension. However, its real efficacy is now in doubt with the blinded SYMPLICITY HTN-3 trial that showed no significant difference in change in office and mean 24-h ambulatory systolic blood pressure between RSDN and sham-procedure arms.

- Reasons for possible discrepancy in results in the three SYMPLICITY HTN trials are discussed.

Heart failure

- Rationale for potential application of RSDN in heart failure (HF) is provided in the form of numerous studies showing the role of hyperactivation of the SNS in reduced ejection fraction HF and in the cardiorenal syndrome and its association with increased mortality.

- The established beneficial role of pharmacological inhibition of the SNS and renin-angiotensin-aldosterone systems in HF management provides indirect evidence of the potential benefit of RSDN in HF.

- Numerous ongoing studies of RSDN in reduced ejection fraction HF and preserved ejection fraction HF are discussed.

Cardiac arrhythmia

- The autonomic nervous system role in pathophysiology of cardiac arrhythmia is outlined.

- New studies of the potential benefit of RSDN in cardiac arrhythmia management are discussed.

Renal disease

- Rationale for potential application of RSDN in renal disease is provided in the form of numerous studies showing the role of hyperactivation of the SNS in renal disease with or without hypertension.

- RSDN has been shown to be safe and efficacious in patients with resistant hypertension and stage 3-4 chronic kidney disease.

Sleep-disordered breathing

- Sleep-disordered breathing is highly prevalent in patients with resistant hypertension.

- Rationale for potential application of RSDN in sleep-disordered breathing is provided in the form of numerous studies showing the role of hyperactivation of the SNS in patients with sleep-disordered breathing.

Insulin resistance

- Sympathetic hyperactivity has been observed with obesity, insulin resistance and the metabolic syndrome.

- There is high prevalence of insulin resistance in patients with essential hypertension.

- Studies suggestive of the potential role of percutaneous RSDN as a nonpharmaceutical approach for treating insulin resistance with or without drug-resistant hypertension are discussed.

Conclusion

- Percutaneous renal sympathetic denervation is a novel minimally invasive procedure, without the need for permanent device implantation.

- It is a safe procedure, based on the sound principle of breaking of the hypersympathetic activation states at the level of the kidney.

- While its therapeutic role in the treatment of resistant hypertension still requires clarification, there are multiple exciting future potential indications for its use.

- We need to do more research in the therapeutic role of RSDN in various clinical pathologies.

Future perspective

- Educated speculations and hopes of RSDN in future clinical practice are explored.

- Its role in resistant hypertension and HF and other diseased states needs to be further clarified, with potential responder patient groups identified.

- Newer, safer and more convenient methods of RSDN are discussed. 
Financial \& competing interests disclosure

KTG Leong is site PI for CGH, Singapore for Global Symplicity Registry. A Walton is on the Medtronic advisory board, and is a proctor for Medtronic. H Krum has done consultancy work for and received grants from Medtronic. M Schlaich is supported by career fellowships from the NHMRC and is an investigator in studies sponsored by Medtronic. M Schlaich also serves on scientific advisory boards for Abbott (formerly Solvay) Pharmaceuticals, BI, Novartis Pharmaceuti-

\section{References}

1 Sobotka PA, Mahfoud F, Schlaich MP, Hoppe UC, Böhm M, Krum H. Sympatho-renal axis in chronic disease. Clin. Res. Cardiol. 100(12), 1049-1057 (2011).

2 Leong KTG, Walton A, Krum H. Renal sympathetic denervation for the treatment of refractory hypertension. Annu. Rev. Med. 65, 349-365 (2014).

3 Schlaich MP, Hering D, Sobotka PA, Krum H, Esler MD. Renal denervation in human hypertension: mechanisms, current findings, and future prospects. Curr. Hypertens. Rep. 14(3), 247-253 (2012).

4 Krum H, Schlaich M, Whitbourn R et al. Catheter-based renal sympathetic denervation for resistant hypertension: a multicentre safety and proof-of-principle cohort study. Lancet 373, 1275-1281 (2009).

5 Esler MD, Krum H, Sobotka PA et al. Renal sympathetic denervation in patients with treatment-resistant hypertension (the Symplicity HTN-2 trial): a randomised controlled trial. Lancet 376, 1903-1909 (2010).

6 Krum H, Schlaich MP, Sobotka PA et al. Percutaneous renal denervation in patients with treatment-resistant hypertension: final 3-year report of the Symplicity HTN-1 study. Lancet 383, 622-629 (2014).

7 Schmieder RE, Redon J, Grassi G et al. ESH position paper: renal denervation - an interventional therapy of resistant hypertension. J. Hypertens. 30(5), 837-841 (2012).

8 Mancia G, Fagard R, Narkiewicz K et al. Task Force Members. 2013 ESH/ESC Guidelines for the management of arterial hypertension: the Task Force for the management of arterial hypertension of the European Society of Hypertension (ESH) and of the European Society of Cardiology (ESC). J. Hypertens. 31, 1281-1357 (2013).

9 Bhatt DL, Kandzari DE, O'Neill WW et al. A controlled trial of renal denervation for resistant hypertension. N. Engl. J. Med. 370, 1393-1401 (2014).

10 Landsberger HA. Hawthorne Revisited: Management and the Worker, Its Critics, and Developments in Human Relations in Industry. Studies in Industrial and Labor Relations of the New York State School of Industrial Relations, Cornell University, Ithaca, NY, USA (1958).

11 Böhm M. The global SYMPLICITY registry: safety and effectiveness of renal artery denervation in real world patients with uncontrolled hypertension. Presented at: American College of Cardiology/i2 Scientific Session, Washington, DC, USA, 30 March 2014. cals and Medtronic and has received honoraria and travel support from Abbott, BI, Servier, Novartis and Medtronic. The authors have no other relevant affiliations or financial involvement with any organization or entity with a financial interest in or financial conflict with the subject matter or materials discussed in the manuscript apart from those disclosed.

No writing assistance was utilized in the production of this manuscript.

12 European Society of Hypertension. www.eshonline.org

13 Heidenreich PA, Trogdon JG, Khavjou OA et al. Forecasting the future of cardiovascular disease in the United States: a policy statement from the American Heart Association. Circulation 123, 933-944 (2011).

14 Parati G, Esler M. The human sympathetic nervous system: its relevance in hypertension and heart failure. Eur. Heart J. 33, 1058-1066 (2012).

15 Malpas SC. Sympathetic nervous system overactivity and its role in the development of cardiovascular disease. Physiol. Rev. 90, 513-557 (2010).

16 Hasking G, Esler M, Jennings G, Burton D, Johns J, Korner P. Norepinephrine spillover to plasma in congestive heart failure: evidence of increased overall and cardiorenal sympathetic nervous activity. Circulation 73, 615-621 (1986).

17 Bock JS, Gottlieb SS. Cardiorenal syndrome: new perspectives. Circulation 121, 2592-2600 (2010).

18 Cohn JN, Levine TB, Olivari MT et al. Plasma norepinephrine as a guide to prognosis in patients with chronic congestive heart failure. N. Engl. J. Med. 311, 819-823 (1984).

19 Kaye DM, Lefkovits J, Jennings GL, Bergin P, Broughton A, Esler MD. Adverse consequences of high sympathetic nervous activity in the failing human heart. J. Am. Coll. Cardiol. 26, 1257-1263 (1995).

20 Hillege HL, Girbes AR, de Kam PJ et al. Renal function, neurohormonal activation, and survival in patients with chronic heart failure. Circulation 102, 203-210 (2000).

21 Petersson M, Friberg P, Eisenhofer G, Lambert G, Rundqvist B. Long-term outcome in relation to renal sympathetic activity in patients with chronic heart failure. Eur. Heart J. 26, 906-913 (2005).

22 Yancy CW, Jessup M, Bozkurt B et al. American College of Cardiology Foundation; American Heart Association Task Force on Practice Guidelines. 2013 ACCF/AHA guideline for the management of heart failure: a report of the American College of Cardiology Foundation/American Heart Association Task Force on Practice Guidelines. J. Am. Coll. Cardiol. 62(16), e147-e239 (2013).

23 Cohn JN, Pfeffer MA, Rouleau J et al. Adverse mortality effect of central sympathetic inhibition with sustained-release moxonidine in patients with heart failure (MOXCON). Eur. J. Heart Fail. 5(5), 659-667 (2003). 
24 Nozawa T, Igawa A, Fujii $\mathrm{N}$ et al. Effects of long-term renal sympathetic denervation on heart failure after myocardial infarction in rats. Heart Vessels 16(2), 51-56 (2002).

25 Villarreal D, Freeman RH, Johnson RA, Simmons JC. Effects of renal denervation on postprandial sodium excretion in experimental heart failure. Am. J. Physiol. 266(5 Pt 2), R1599-R1604 (1994).

26 Clayton SC, Haack KK, Zucker IH. Renal denervation modulates angiotensin receptor expression in the renal cortex of rabbits with chronic heart failure. Am. J. Physiol. Renal. Physiol. 300, F31-F39 (2011).

27 Davies JE, Manisty CH, Petraco R et al. First-in-man safety evaluation of renal denervation for chronic systolic heart failure: primary outcome from REACH-Pilot study. Int. J. Cardiol. 162, 189-192 (2013).

28 Verloop WL, Beeftink MM, Nap A et al. Renal denervation in heart failure with normal left ventricular ejection fraction. Rationale and design of the DIASTOLE (DenervatIon of the renAl Sympathetic nerves in hearT failure with nOrmal Lv Ejection fraction) trial. Eur. J. Heart. Fail. 15(12), 1429-1437 (2013).

29 Pocock SJ, Wang D, Pfeffer MA et al. Predictors of mortality and morbidity in patients with chronic heart failure. Eur. Heart J. 27, 65-75 (2006).

30 Flannery G, Gehrig-Mills R, Billah B, Krum H. Analysis of randomized controlled trials on the effect of magnitude of heart rate reduction on clinical outcomes in patients with systolic chronic heart failure receiving beta-blockers. $A m$. J. Cardiol. 101, 865-869 (2008).

31 Swedberg K, Komajda M, Böhm M et al. On behalf of the SHIFT Investigators. Ivabradine and outcomes in chronic heart failure (SHIFT): a randomized placebo controlled study. Lancet 376, 875-885 (2010).

32 Del Pace $S$, Parodi G, Bellandi B et al. Tuscany registry of Tako-tsubo cardiomyopathy. Anxiety trait in patients with stress-induced cardiomyopathy: a case-control study. Clin. Res. Cardiol. 100, 523-529 (2011).

33 Tomaselli GF, Zipes DP. What causes sudden death in heart failure? Circ. Res. 95, 754-763 (2004).

34 Komajda M, Follath F, Swedberg K et al. The Euro Heart Failure Survey programme; a survey on the quality of care among patients with heart failure in Europe. Part 2: treatment. Eur. Heart J. 24, 464-474 (2003).

35 Zipes DP. Heart-brain interactions in cardiac arrhythmias: role of the autonomic nervous system. Cleve. Clin. J. Med. 75(Suppl. 2), S94-S96 (2008).

36 Dorian P. Antiarrhythmic action of beta-blockers: potential mechanisms. J. Cardiovasc. Pharmacol. Ther. 10(Suppl. 1), S15-S22 (2005).

37 Moss AJ, Schwartz PJ, Crampton RS, Locati E, Carleen E. The long QT syndrome: a prospective international study. Circulation 71, 17-21 (1985).

38 Verrier RL, Josephson ME. Impact of sleep on arrhythmogenesis. Circ. Arrhythm. Electrophysiol. 2, 450-459 (2009).

39 Ukena C, Mahfoud F, Linz D, Böhm M, Neuberger HR. Potential role of renal sympathetic denervation for the treatment of cardiac arrhythmias. EuroIntervention 9(Suppl. R), R110-R116 (2013).

40 Pokushalov E, Romanov A, Corbucci G et al. A randomized comparison of pulmonary vein isolation with versus without concomitant renal artery denervation in patients with refractory symptomatic atrial fibrillation and resistant hypertension. J. Am. Coll. Cardiol. 60, 1163-1170 (2012).

41 Ukena C, Bauer A, Mahfoud F et al. Renal sympathetic denervation for treatment of electrical storm: first-in-man experience. Clin. Res. Cardiol. 101, 63-67 (2012).

42 Schlaich MP, Socratous F, Hennebry S et al. Sympathetic activation in chronic renal failure. J. Am. Soc. Nephrol. 20, 933-939 (2009).

43 Zoccali C, Mallamaci F, Parlongo S et al. Plasma norepinephrine predicts survival and incident cardiovascular events in patients with end-stage renal disease. Circulation 105(11), 1354-1359 (2002).

44 Amann K, Rump LC, Simonaviciene A et al. Effects of low dose sympathetic inhibition on glomerulosclerosis and albuminuria in subtotally nephrectomized rats. J. Am. Soc. Nephrol. 11, 1469-1478 (2000).

45 Vonend O, Marsalek P, Russ H, Wulkow R, Oberhauser V, Rump LC. Moxonidine treatment of hypertensive patients with advanced renal failure. J. Hypertens. 21, 1709-1717 (2003).

46 Strojek K, Grzeszczak W, Gorska J, Leschinger MI, Ritz E. Lowering of microalbuminuria in diabetic patients by a sympathicoplegic agent: novel approach to prevent progression of diabetic nephropathy? J. Am. Soc. Nephrol. 12, 602-605 (2001).

47 Hausberg M, Tokmak F, Pavenstadt H, Kramer BK, Rump LC. Effects of moxonidine on sympathetic nerve activity in patients with end-stage renal disease. J. Hypertens. 28, 1920-1927 (2010).

48 Hering D, Mahfoud F, Walton AS et al. Renal denervation in moderate to severe chronic kidney disease. J. Am. Soc. Nephrol. 23, 1250-1257 (2012).

49 Luippold G, Beilharz M, Muhlbauer B. Chronic renal denervation prevents glomerular hyperfiltration in diabetic rats. Nephrol. Dial. Transplant. 19(2), 342-347 (2004).

50 Pontremoli R, Viazzi F, Martinoli C et al. Increased renal resistive index in patients with essential hypertension: a marker of target organ damage. Nephrol. Dial. Transplant. 14, 360-365 (1999).

51 Mahfoud F, Cremers B, Janker J et al. Renal hemodynamics and renal function after catheter-based renal sympathetic denervation in patients with resistant hypertension. Hypertension 60 (2), 419-424 (2012).

52 Logan AG, Perlikowski SM, Mente A et al. High prevalence of unrecognized sleep apnoea in drug-resistant hypertension. J. Hypertens. 19, 2271-2277 (2001).

53 Somers VK, White DP, Amin R et al. Sleep apnea and cardiovascular disease: an American Heart Association/ American College Of Cardiology Foundation Scientific Statement from the American Heart Association Council for High Blood Pressure Research Professional Education Committee, Council on Clinical Cardiology, Stroke Council, 
and Council On Cardiovascular Nursing, in collaboration with the National Heart, Lung, and Blood Institute National Center on Sleep Disorders Research (National Institutes of Health). Circulation 118, 1080-1111 (2008).

54 Grassi G, Facchini A, Trevano FQ et al. Obstructive sleep apnea-dependent and -independent adrenergic activation in obesity. Hypertension 46, 321-325 (2005).

55 Witkowski A, Prejbisz A, Florczak E et al. Effects of renal sympathetic denervation on blood pressure, sleep apnea course, and glycemic control in patients with resistant hypertension and sleep apnea. Hypertension 58, 559-565 (2011).

56 Masuo K, Mikami H, Ogihara T, Tuck ML. Sympathetic nerve hyperactivity precedes hyperinsulinemia and blood pressure elevation in a young, non-obese Japanese population. Am. J. Hypertens. 10, 77-83 (1997).
57 Mancia G, Bousquet P, Elghozi JL et al. The sympathetic nervous system and the metabolic syndrome. J. Hypertens. 25 , 909-920 (2007)

58 Lima NK, Abbasi F, Lamendola C, Reaven GM. Prevalence of insulin resistance and related risk factors for cardiovascular disease in patients with essential hypertension. Am. J. Hypertens. 22, 106-111 (2009).

59 Mahfoud F, Schlaich M, Kindermann I et al. Effect of renal sympathetic denervation on glucose metabolism in patients with resistant hypertension: a pilot study. Circulation 123 , 1940-1946 (2011).

60 Schlaich MP, Straznicky N, Grima M et al. Renal denervation: a potential new treatment modality for polycystic ovary syndrome. J. Hypertens. 29(5), 991-996 (2011). 